\title{
Motivating contributions to online forums: can locus of control moderate the effects of interface cues?
}

\author{
Hyang-Sook Kim ${ }^{\mathrm{a}}$ and S. Shyam Sundar ${ }^{\mathrm{b}}$ \\ aDepartment of Mass Communication \& Communication Studies, Towson University; bedia \\ Effects Research Laboratory, The Pennsylvania State University
}

\begin{abstract}
In an effort to encourage users to participate rather than lurk, online health forums provide authority badges (e.g., guru) to frequent contributors and popularity indicators (e.g., number of views) to their postings. Studies have shown the latter to be more effective, implying that bulletin-board users are motivated by external validation of their contributions. However, no consideration has yet been given to individual differences in the influence of such popularity indicators. Personality psychology suggests that individuals with external, rather than internal, locus of control are more likely to be other-directed and therefore more likely to be motivated by interface cues showing the bandwagon effect of their online posts. We investigate this hypothesis by analyzing data from a 2 (high vs. low authority cue) $\times 2$ (strong vs. weak bandwagon cue) experiment with an online health community. Results show that strong bandwagon cues promote sense of community among users with internal, rather than external, locus of control. When bandwagon cues are weak, bestowal of high authority serves to heighten their sense of agency. Contrary to prediction, weak bandwagon cues appear to promote sense of community and sense of agency among those with external locus of control. Theoretical and practical implications are discussed.
\end{abstract}

Most users simply lurk in online health communities to seek information, rather than contributing (Mo \& Coulson, 2010). In fact, only $6 \%$ of Internet users actually generate health information, while $41 \%$ of them report reading health information posted by other users in online news groups, websites, and blogs (Fox \& Jones, 2009). In large communities, users feel anonymous and do not feel the responsibility to contribute (Karau \& Williams, 1995; Latané, 1981; Oliver \& Marwell, 1988). However, for the continued vitality of Web 2.0 as a venue for effective health communications, it is important that individuals participate in larger numbers by contributing new information, refuting dubious information posted by others, engaging in discussion about health and medical practices, and offering social support to others in need. As critical- mass theorists argue (e.g., Oliver \& Marwell, 1988), a community needs to not only have depth of information resulting from dominance of a small number of frequent contributors (i.e., a critical mass), but also focus on a wide range of information from a diverse pool of contributors (Thorn \& Connolly, 1987). These efforts of "collective actions" (Prasarnphanich \& Wagner, 2011, p. 2065) are particularly important to online health communities in order to increase the probability of individual users' satisfaction with information and social support that caters to their needs (e.g., Curtrona, 1990; Hann et al., 2002; Wright, Johnson, Bernard, \& Averbeck, 2011).

Tangible solutions for this issue have not been empirically investigated despite evidence of undercontribution of health information sharing (Fox \& Jones, 2009). Most previous studies have focused on identifying individuals' motivations for taking part in online support communities as members (e.g., Barak, Boniel-Nissim, \& Suler, 2008; Buchanan \& Coulson, 2007; Ling et al., 2005; Preece, Nonnecke, \& Andrews, 2004).

Although motivations to become members may be universal, not all users are identical in their tendency to share emotional and cognitive resources online. Prior research suggests that personal traits may dictate who seeks and contributes information to online forums. Individuals who believe that they lack control over their lives (i.e., external locus of control) tend to exhibit greater need for social support than those who are fully confident about their actions and consequences of the actions (i.e., internal locus of control) (Vanderzee, Buunk, \& Sanderman, 1997). Sometimes such traits can be acquired throughout one's lifetime, especially when going through different types of diseases (Wallston, 1992). The traits vary among patients, and eventually exert different degrees of coping with health behaviors (Bettencourt, Talley, Molix, Schlegel, \& Westgate, 2008; Chen, Deng, \& 
In addition to influencing one's attitude toward health behaviors, locus of control can be quite predictive of one's online activities, including online sharing. Hoffman, Novak, and Schlosser (2003) have shown that online consumers with a strong external locus of control are more likely to rely on Internet use as a substitute for their life activities compared to those with a strong internal locus of control, who tend to be goal-directed in using the Internet. The locus of control also appears as a strong predictor that determines users' information-sharing tendency (i.e., electronic word-ofmouth). Users with strong external locus of control prefer a group to which they already belong while those with strong internal locus of control explore new communities to spread their word (Lam \& Mizerski, 2005).

Given such clear differences due to internal versus external locus of control, both in the way individuals use the Internet and in the way they approach their health, it is likely that this individualdifference variable plays a role in motivating users of online health forums to share their knowledge. This has implications for the kinds of appeals that designers of such forums ought to employ to attract more contributions from users. Current practices, such as awarding authority badges to frequent contributors and providing popularity indicators of their posts, may be differentially appealing to those with different levels of internal and external loci of control. Thus, the present study explores the moderating role played by locus of control in dictating the effects of interface cues upon users' motivations to contribute to online health forums.

We begin by discussing the reasons for the general resistance to posting in online forums. We then present technological solutions, in the form of interface cues, for motivating users. Finally, we propose a theoretical rationale for the moderating effects of locus of control.

\section{Why don't lurkers post information?}

Certain motivations, such as obtaining information while in need, seeking emotional support from other users, and maintaining relationships within the community, vary between two groups of users: posters and lurkers. Posters are willing to contribute information to the community by asking questions, commenting on others' questions, or replying to others' comments, while lurkers merely wander around the community to obtain the information they want (Preece et al., 2004). Contributors are more likely to check in on the community (as a routine part of their life) than lurkers, and although both contributors and lurkers visit the community in order to obtain necessary information, lurkers tend to express less overall satisfaction with the community (van Uden-Kraan et al., 2008). This is somewhat disconcerting given the reality of significantly more lurkers than posters (Fox \& Duggan, 2013; Fox \& Jones, 2009; Mo \& Coulson, 2010).

Previous studies have explored how posters' and lurkers' motivations to contribute to the community differ in the health communication context. An online survey of members of HIV/AIDS online communities found that those who posted questions and commented on others' questions showed greater levels of enjoyment with the contribution itself and altruistic behaviors (in addition to feelings of being connected with the community) than members who only consume others' input (Mo $\&$ Coulson, 2010). Another survey with a large number of MSN users in online discussion board communities found that posters showed a greater sense of community than did lurkers. In addition, the study identified specific reasons that discouraged lurkers from contributing to online communities: (1) They did not value posting activity beyond owning a membership and browsing others' posts or (2) they were reluctant to post out of shyness (Preece et al., 2004).

Bishop (2007) proposed a theoretical model to explain the difference between lurkers and posters in terms of desirability and satisfaction, which are ultimately responsible for motivating online community users to engage in posting activities. The model theorized that once users desire to obtain membership in an online community for whatever reason, for instance, to procure helpful information (level 1), they either feel the need to help other users by creating their own posts (or observing others' posts) or they fail to perceive posting activities as being helpful (level 2). In the first level 2 case, users will assess their ability to contribute content to the community (level 3 ). If they find themselves capable of posting content and believe that they are helping other users, they will share information with others. Normally, lurkers remain in the second level 2 stage, either because they do not find it helpful to post (Bishop, 2007) or because their occasional forays into posting did not result in meaningful community feedback (Zhang \& Storck, 2001). Therefore, it is important to guide community users who typically remain as non-contributors or "peripheral members" (Zhang \& Storck, 2001, p. 5) to go beyond the level 2 stage and contribute, for the overall success of the online community (Bishop, 2007). 


\section{Motivations to contribute to online communities}

In general, users join online communities to gain information and/or social support, enhance selfconfidence, and socialize with other users. People are willing to share knowledge in online communities for (a) actual benefits from the network (i.e., "tangible returns") such as cognitive resources and instrumental aids (Ridings \& Gefens, 2004), (b) psychological rewards from participation (i.e., "intangible returns"), and (c) perceived connectedness with the community network (i.e., "community interest") (Wasko \& Faraj, 2000, p. 163). An online survey of a usergenerated encyclopedia (i.e., Everything2.com) also revealed self-entertainment, satisfaction with the community, and belongingness to the community as major reasons for visiting the site. Anonymous users, however, indicated acquisition of information was an important reason for joining the community (Lampe, Walsh, Velasquez, \& Ozkaya, 2010).

Likewise, resources - the most important factor for community sustainability — are not limited to functional aspects of information sharing (i.e., information supply and consumption), but rather extended to psychological aspects (i.e., self-enhancement, community attachment and belongingness, enjoyment, etc.). Previous literature has suggested strong correlations between these motivations of information sharing and actual contribution to one of the biggest platforms of online sharing - wiki applications. A study of Wikipedians reported strong correlations between psychological motivations (i.e., belongingness, activity enjoyment, self-enhancement, and self-development) and contribution levels. These psychological motivations for content contribution are mainly self-focused. In fact, Wikipedians scored higher on openness to others and self-orientation than non-Wikipedians (Amichai-Hamburger, Lamdan, Madiel, \& Hayat, 2008). Self-identification of Wikipedians to "ethos-action community" (Pentzold, 2010, p. 717) may be unique compared to other online community users because Wikipedians exhibit strong commitment (i.e., an average contribution of 8.27 hours per week among highly committed users who have created their personal user pages) toward the community and community members that they know (Nov, 2007). In particular, the more committed they are, the greater is their contribution to enriching quality of the content (Zhao, Zhang, Wagner, \& Chen, 2013). However, general online community users, including those in health communities, do not spend that much time offering resources based on professional commitment. Rather, they are willing to contribute to the community when they have strong motivations of altruism, enjoyment, and efficacy from their participating actions (e.g., Oh, 2012).

\section{Can technology change lurkers' minds about becoming posters?}

Then the question is, how can organizations hosting health message boards motivate users to contribute? Studies have found that interface cues imbuing "sourceness" to the self are successful in promoting users' motivations to generate information (Su, 2012; Yuan, Bazarova, Fulk, \& Zhang, 2013), such as demonstrating one's abilities, empowering oneself, and fulfilling duties of community membership, which can satisfy self-oriented motivations for contribution (Ma \& Agarwal, 2007; Tedjamulia, Olsen, Dean, \& Albrecht, 2005; Wasko \& Faraj, 2005). As the agency model argues, a strong sense of "self as source" of an interaction translates into higher involvement with the content, greater sense of identity, and higher control felt by the user while interacting online (Sundar, 2008). Similarly, Tedjamulia et al. (2005) proposed a model to explain the mechanisms behind information sharing in online communities based on personal motivations for contributing content, including selfefficacy, intrinsic motivation, the need to achieve, and trust in the community. They assessed these motivations as a function of technological features conveying the values of others' feedback (e.g., replies or comments on message boards) and visible reinforcements for content ownership (e.g., membership seals, users' past activities/membership history, or point rewards). Similar technological artifacts (e.g., users' ranking/ reputation and activity history), along with others' feedback (e.g., helpfulness and number of threads), also positively impact user identity and therefore predict users' contributions (Ma \& Agarwal, 2007).

For instance, a reputation cue that signaled the level of user's history of activity has been shown to promote user contribution in an online employee community (Farzan et al., 2008). Specifically, the reputational cue (i.e., beehive) in the community website represented point-based status classes (i.e., new bee, worker bee, busy bee, and super bee) based on users' activities, such as uploading photos (5 points), updating their profiles by adding text (10 points), and commenting on others' profiles (15 points). The result over 6 weeks showed that the point-based reputation cue system led to greater contributions to the community site when overall point details were available to review. Another effective technique is to prime users with reputational treatment (i.e., how likely it is that the users' participation will be evaluated by the website, i.e., uniqueness). When users perceive their contributions as special to the community, they express greater intention to contribute (Ling et al., 2005). 
The technological artifacts operationalized in previous studies can be categorized into two types of interface cues: authority cues and bandwagon cues (Sundar, Xu, \& Oeldorf-Hirsch, 2009). While authority cues convey the pedigree of the posters' expertise, bandwagon cues signal a poster's popularity among community users. The number of posts and membership history or membership badge are forms of authority cues, whereas the number of views, replies, or comments and star ratings of a posting's helpfulness are forms of bandwagon cues. The nature of online information sharing requires both types of cues in order to satisfy the inseparable relationship between the "self as source" and "other users as source" (Sundar \& Nass, 2001).

\section{Do interface cues work for everyone?}

Considering that the activity of online sharing requires users to be vigilant of their actions and interactions with other users, their personal propensity relating to the environment should be taken into consideration. For instance, individuals who have greater confidence with what they do in life might not show the same attitudes toward posting activities as those who are less certain about their behavior and its consequences. On the other hand, individuals who are susceptible to external influences and believe that influences from powerful others are inevitable might demonstrate more passive attitudes about information sharing, and may thus want to become informed by other users in the community. This individual-difference variable is called locus of control (LOC). Rotter (1954) explicated two personality traits - internal LOC and external LOC-based on the notion of reinforcement, which is "an empirical law of effect" and refers to an event or occurrence that increases the possibility of one's behaviors in a predictable direction based on one's behavior patterns as manifested in previous events (Rotter, 1954, p. 112). "A reinforcement acts to strengthen an expectancy that a particular behavior or event will be followed by that reinforcement in the future" (Rotter, 1966, p. 2). Individuals develop their own belief in causality between an event and an outcome based on their experience with similar cause-and-effect occurrences. An individual's disposition to LOC orientations is the result of generalized expectancies toward reinforcement. The LOC orientations are distinguished by different reinforcements. Internal LOC is akin to an event or environment in which some value for the person is heightened (i.e., internal reinforcement), whereas external LOC refers to an event or environment that yields benefits for the group or culture to which the person belongs (i.e., external reinforcement). Likewise, the differential propensity to the two types of reinforcements as drivers for behaviors predicts the differential behaviors of individuals with internal and external LOC. Given this formulation, the authority cues that signal a user's own values, in the form of his or her expertise and track record of contributions, are likely to operate as internal reinforcements, and hence have stronger influence on the behaviors of those members of the online community with internal, rather than external, LOC. On the other hand, the bandwagon cues that focus on such community characteristics as connectedness, in-group contribution, and discussions are likely to operate as external reinforcements, with stronger effects on the behavior of users with external, rather than internal, LOC.

\section{Expectancies of behavioral outcomes of loci of control in health context}

Previous research has shown close connections between one's LOC and health status and behaviors with regard to coping mechanisms (Bettencourt et al., 2008; Chen et al., 2001; De Valck \& Vinck, 1996; Wallston, 1992, 2005). While developing the concept of "Health LOC," Wallston $(1992,2005)$ suggested that the original LOC developed by Rotter (1990) is a personality trait rather than a state. The personality trait determines "behavioral potentials" or "likelihood of behaviors occurring in a specific situation." However, LOC pertains to "generalized expectancies" toward the likelihood, as well as "values" of reinforcing such behaviors in similar situations. The latter component is critical to health-related behaviors (Wallston, 2005, p. 628). Therefore, when individuals suffer from critical diseases such as cancer, they tend to value internal reinforcements of the outcome (e.g., selfconfidence to overcome the disease) rather than external ones (e.g., medical treatment). This value assessment of the behavior, in turn, can influence one's LOC orientation. In fact, extant literature shows empirical evidence of strong internal LOC among patients who are diagnosed with cancer (Bettencourt et al., 2008; De Valck \& Vinck, 1996). On the other hand, patients with depression exhibit passive action to treat the symptom of the disorder, rather than showing a willingness to overcome it. Thus, they readily reinforce external LOC (Wallston \& Wallston, 1978).

\section{Locus of control, source cues, and psychology of "sourceness" for online contribution}

The literature reveals similar variation in the propensity for reinforcements and outcome expectancies in the domain of online sharing activities among e-health consumers with internal and external LOC. Those with internal LOC are better equipped for searching and making use of information to satisfy their needs than those with external LOC (Lefcourt, Gronnerud, \& McDonald, 1973; Wolk \& DuCette, 1974). Sandler and Lakey (1982) conducted a survey of college students about both negative 
and positive life events, controllability over those events, and perception of the social support effectiveness in relation to susceptibility to psychological disorders such as depression. They found that those with external LOC considered the amount of support that they received to be important regardless of how likely it was that such support was useful to their coping with stress. On the other hand, those with internal LOC actively made use of the social support for reducing their stress. Therefore, it is suggested that those with external LOC might be prone to others' attention (i.e., environmental reinforcement) to their action in an online community, while those with internal LOC would value their own actions for seeking help in the community or even providing help to others (i.e., perceived control as reinforcement), without being affected by attention from others in the community.

Lam and Mizerski (2005) also found that individuals with external LOC showed greater propensity for in-group electronic word-of-mouth (eWOM) activities, possibly due to their heavy reliance on environment/external forces to determine their actions and consequences. On the other hand, those with internal LOC generally chose to partake in out-group eWOM activities because they were willing to exhibit their own power in eWOM activities by exploring other new communities. One could argue that eWOM and online information sharing on a community message board are not identical activities because the former requires a strong viral component (Hennig-Thurau, Gwinner, Walsh, \& Gremler, 2004), while the latter does not necessarily require the rapid spread of information across online networks. However, these activities are similar in that they both grant "sourceness" to users, that is, afford them the ability to serve as "communication sources" rather than being passive receivers of communication.

\section{How can users be empowered by posting activities?}

If indeed interface cues boost users' motivations to post content, what are the underlying psychological mechanisms? A study of the empowerment potential of blogging found that a higher number of comments resulted in greater feelings of belonging to the community (i.e., sense of community, or SOC), while a higher number of site visits led to feelings of competence, assertiveness, and confidence in blogging (i.e., sense of agency, or SOA) (Stavrositu \& Sundar, 2012). These two psychological states ultimately enhanced users' psychological empowerment (i.e., sense of influence, or SOI). In addition, participants' interest in blogging was also positively correlated with the number of site visits. Blog-interface metrics such as the number of site visits and the number of comments are analogous to bandwagon cues that were investigated by Kim and Sundar (2011), who found a positive effect of these cues on both sense of community and user contributions to an online forum. In a controlled laboratory experiment, four different bandwagon cues - the number of views, number of replies, the number of times the thread was shared, and star ratings of the thread's helpfulness - were manipulated to convey either weak or strong bandwagon for the message posted by the study participant a week ago. The high level of the community feedback delivered by the bandwagon cues served to increase participants' sense of community as well as intention to post in the message board. In particular, participants' perception of how many times the thread (initiated by participants' question) was shared tended to positively affect community belongingness and psychological empowerment, resulting in more positive attitudes toward posting and posting intentions (Kim \& Sundar, 2011).

In addition, authority cues that signal users' expertise and reputation through community membership seals or user history might also impact users' perceptions of their capabilities to be helpful to other users, as well as of their ability to post. In this case, those authority cues were expected to reinforce one's SOA (Kim \& Sundar, 2011). In fact, the posters' motivations such as belongingness, activity enjoyment, self-enhancement, and self-development (e.g., Amichai-Hamburger et al., 2008; Lampe et al., 2010) are conceptually similar to SOC and SOA. Posters show greater feelings of not only being connected to other users in the community (i.e., SOC) but also being able to help them (i.e., SOA) (Mo \& Coulson, 2010, 2012; van Uden-Kraan, Drossaert, Taal, Seydel, \& van de Laar, 2008).

In fact, the propensity for LOC centeredness - self or others - may be conceptually aligned with the relationships between two types of source cues (i.e., authority and bandwagon cues) and SOA and SOC, respectively. Users with strong internal LOC, which is akin to self-focused reinforcement to act and to congruent outcomes, will likely experience higher SOA due to the self-enhancement and self-development afforded by authority cues. On the other hand, users with strong external LOC, given their tendency for other-focused reinforcement, will likely experience higher SOC when the bandwagon cues articulate connectedness to the community. Thus, we can expect internal and external LOC to moderate the effects of the two types of interface cues on SOA and SOC. However, typical interfaces of online health communities offer members both authority and bandwagon cues simultaneously, rather than separately. Our previous work has examined interaction effects of these two "source cues" on individuals' attitudes and intention related to community contribution activities (Kim \& Sundar, 2011), but we do not know whether LOC traits will moderate the combined effect of 
authority and bandwagon cues in persuading community users to contribute. Therefore, we examine three-way interactions between the two source cues and LOC on psychological variables, as hypothesized in the following. Table 1 shows the experimental conditions with the number of participants in each condition.

H1. Internal LOC (i.e., those on the lower end of the LOC scale), rather than external LOC (i.e., those on the higher end of the LOC scale), will be more responsive to a high-authority cue (signaling user expertise) than a low-authority cue and therefore show more positive attitudes toward posting activities.

H2. Internal, rather than external, LOC will be more responsive to a high-authority cue (signaling user expertise) than a low-authority cue and therefore show greater intention to post.

H3. External, rather than internal, LOC will be more responsive to strong bandwagon cues (signaling the popularity and helpfulness of user contribution) than weak bandwagon cues and therefore show positive attitudes toward posting activities.

H4. External, rather than internal, LOC will be more responsive to strong bandwagon cues (signaling the popularity and helpfulness of user contribution) than weak bandwagon cues and therefore show greater intention to post.

H5. Users with internal LOC will show greater SOA when they receive a high authority cue than low one (H5a), whereas users with external LOC will show greater SOC when they receive strong bandwagon cues than weak ones ( $\mathrm{H} 5 \mathrm{~b})$.

H6. The interactions between the authority and bandwagon cues on attitudes toward posting activities (H6a), intention to post (H6b), SOA (H6c), and SOC (H6d) will differ as a function of LOC.

\section{Methods}

In a 2 (authority cues high vs. low) $\times 2$ (bandwagon cues strong vs. weak) between-participants factorial experiment examining the effects of the two source cues on users' intentions to contribute to a health community website, participants' personality trait regarding LOC was measured before exposure to the site. A prototype health community website, modeled after Healthboards.com, a popular online health community website (Alexa.com, 2010), was developed especially for this experiment, as described later in the Stimulus subsection.

In Healthboards.com, posters and repliers serve as contributors. When posters ask questions about health issues on a message board, repliers answer the question. The activities of both posters and repliers construct a series of conversations on the message board (i.e., a thread). In the current study, all participants were asked to be posters, and they received other users' feedback over a week-long period, as part of the procedure of the current study. Eighty-three undergraduates, 65 of whom were females, recruited from several communication classes in a large U.S. university participated in the study. ${ }^{1}$

Table 1. Mean scores (and standard deviations in parentheses) on dependent measures.

\begin{tabular}{lllll}
\hline & \multicolumn{2}{c}{ Online guru } & \multicolumn{2}{c}{ Regular member } \\
\cline { 2 - 5 } & Bandwagon weak & Bandwagon strong & Bandwagon weak & Bandwagon strong \\
\hline Attitude toward posting activity & $4.08(1.12) n=22$ & $4.55(.88) n=19$ & $4.29(1.36) n=21$ & $4.68(0.87) n=22$ \\
Intention to post & $2.53(1.45) n=22$ & $3.44(1.35) n=19$ & $2.84(1.70) n=21$ & $3.47(1.49) n=22$ \\
Sense of agency & $5.26(1.22) n=22$ & $4.98(.78) n=19$ & $5.03(1.44) n=21$ & $5.44(1.07) n=22$ \\
Sense of community & $3.67(1.22) n=22$ & $4.19(.89) n=19$ & $3.77(1.05) n=21$ & $4.21(.86) n=22$ \\
\hline
\end{tabular}

The average age of the participants was 20.4 years $(S D=1.49)$. While the use of student samples is less than ideal for generalizing to the broader population, it is an accepted practice for examining relationships between variables (e.g., Kruglanski, 1975). Moreover, college students tend to be more familiar with online applications, making them ideal for experiments requiring them to participate in online forums.

\section{Procedure}

The experiment involved two steps. After participants provided their consent and finished the

\footnotetext{
${ }^{1}$ It should be noted that more females generally seek health information online than males (see Fox
} \& Jones, 2009). 
prequestionnaire (which included the measures of LOC and control variables), they browsed the stimulus website by logging in using their school e-mail accounts. After browsing and reading one of the target threads on the stimulus website, participants were instructed to post a question about the topic of fitness and nutrition on the health message board. Once they posted a question, they returned to the main page of the stimulus website and clicked their own posting, which appeared at the bottom of the thread list, in order to exit to the main online questionnaire to evaluate the website. ${ }^{2}$ When the participants finished answering the main questionnaire, they were informed about the next step of the study before they left the lab.

The second step of the study was self-administered by participants accessing the online site of their own accord, without any researcher control. One week after the initial step, participants revisited the website in which they had posted their question about fitness and nutrition through the study link for their access to individual experiment webpages sent via e-mail instructions. The instructions also informed participants about how the website awarded them a membership seal. The instructions said, "When you click on your own post, you will notice that you have been awarded a Membership Status. The membership has been assigned to you based on the information that you provided in the lab session of the study regarding your day-to-day online activities." Furthermore, the instructions informed participants that the Online Guru status was considered the highest membership status on the study website.

Participants landed on the exact same main page of the website that they visited during the previous session. The participants accessed the thread page that contained both the authority and bandwagon manipulations by clicking their own post. For example, their post either had a lot of views (200) or a few (21). When the participants finished browsing and reading the thread page, they clicked the questionnaire link at the bottom of the thread page and completed the questionnaire to conclude the study.

\section{Stimulus}

The topic of the website that we created, HealthQ\&A, is fitness and nutrition-one of the most popular topics among college students (Baxter, Egbert, \& Ho, 2008). The main page of the website included the title and author information for the posts, and four different bandwagon cues (see Figure 1). The researchers built a custom Web application, which appeared as a fully functioning community site. However, only actions required for the experimental protocol were clickable (i.e., one of the postings from the thread list and "new thread" to post a question on the main page). Since the first session of the experiment took place in a lab environment, the researcher monitored the participants' activities and instructed them to follow the protocol, which minimized the risk of frustration among participants if they were to click on any inactive parts of the webpages. In addition, the application allowed the researchers to simulate threaded discussions with manipulated source cues such as reputation of each participant, popularity of the thread initiated by the participant's post, and community responses to be customized for the different experimental groups.

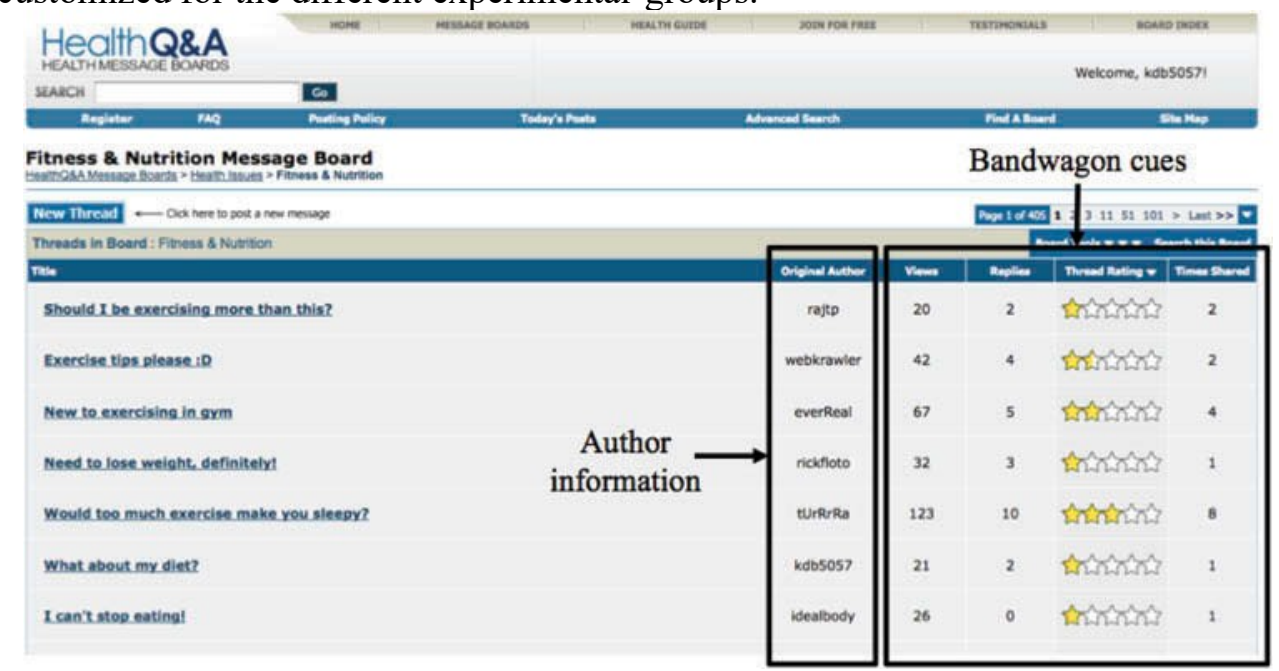

Figure 1. Screen capture of the main page of the experimental website.

${ }^{2}$ The analysis reported here does not use any data from this initial evaluation of the website. They are reported in Kim and Sundar (2011). 


\section{Independent variables}

Authority and bandwagon cues served as the primary independent variables of the experiment. A participant's (poster's) level of source expertise in the online community served as an authority cue. "Online guru" was a membership seal signaling the participant's high level of source expertise with a corresponding image (see Figure 2). On the other hand, "member" was a membership for participants assigned to low authority condition (see Figure 2). However, the authority cue for the other users who replied to the participant's question was identical across the conditions as "member." Bandwagon cues were implemented in four forms commonly used in online communities: number of views (200 vs. 21), number of replies to the thread (12 vs. 2), number of times the thread was shared (12 vs. 1), and a star rating of the thread's helpfulness (four and one-half stars vs. one star) (see Figure 2). The bandwagon cues indicated other users' activities on the message board, and thereby informed participants about how other users evaluated the thread initiated by their post on the message board. The four cues were expected to operate in tandem, as a cluster, together communicating either a strong or a weak bandwagon around their post. Therefore, our design is not set up to examine the efficacy of each one of the four cues separately.
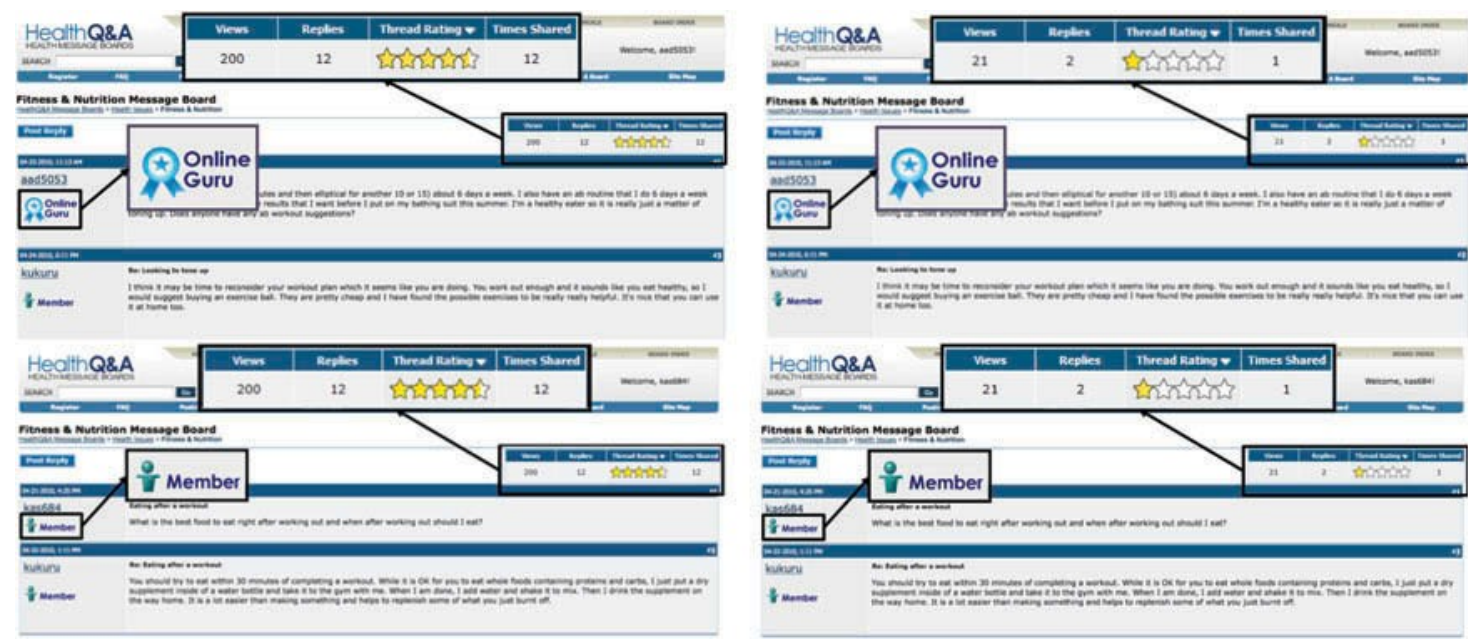

Figure 2. Screen capture of the stimulus website with interface cues for the thread page of the high authority $\times$ strong bandwagon cues (top left), high authority $\times$ weak bandwagon cues (top right), low authority $\times$ strong bandwagon cues (bottom left), and low authority $\times$ weak bandwagon cues (bottom right) experimental conditions.

Each participant's study webpage consisted of html files with manipulations of the authority and bandwagon cues by modifying the site's images and text. One html file for the main page consisted of information about bandwagon cue manipulations. Another html file for the thread page was created to manipulate replies to each participant's question posted on the message board. For the weak bandwagon condition, a research assistant who was blind to the manipulation crafted two core replies. The core replies adequately addressed the original participant's inquiries by offering them the information for which they asked about fitness and nutrition. The research assistant also created 10 replies in agreement with the core replies, for the strong bandwagon condition. This method of crafting replies allowed the study to minimize content effects by deliberately holding constant the amount of information conveyed in the two conditions, even though the number of replies was different across them. The basic strategy behind crafting replies was to provide content that would be relevant to the original question, in order to lend ecological validity to the experimental site and procedure. All health information provided by the research assistant was validated from different sources, such as the American Journal of Clinical Nutrition, Cancer.org, and The New York Times.

\section{Measures}

\section{Manipulation check}

Participants were asked to rate their perceptions of the number of views that the thread had on a scale anchored from very few (1) to a lot (7). The other three bandwagon cues (i.e., number of replies, number of times the post was shared, and the star rating of the thread's helpfulness) were checked using similar questions. The manipulation for the authority cues was assessed through questions 
regarding participants' indication of their membership seal — either online guru or member-and their perceptions of the membership status accorded to them, on a 7-point scale ranging from very low to very high status.

\section{Locus of control}

A total of 14 items measured participants' LOC. Two dimensions of internal and external LOC were assessed by asking participants about the degree to which they usually believe that the outcomes of events are due to either their own capabilities or external forces, on a 7-point Likert scale (Lam \& Mizerski, 2005; Levenson, 1974). Four items that contained the description of the internal LOC trait were reverse coded (e.g., When I get what I want, it's usually because I worked hard for it); thus, higher scores indicate high external LOC while lower scores indicate high internal LOC $(M=$ $3.43, S D=.67, \alpha=.76$ ).

\section{Sense of community and sense of agency}

In total, 22 items on a 7-point scale anchored between not at all and a lot measured the likelihood of certain outcomes from their activities (i.e., posting a question or potentially replying to the thread) among participants. An exploratory factor analysis resulted in two indices - sense of agency (SOA) and sense of community (SOC). Three items for SOA referred to one's competence, assertiveness, and confidence (e.g., I have control over my own voice; $\alpha=.71$ ), whereas 12 items for SOC referred to one's expectations of interacting with other users in the network (e.g., It may well become very important to me to interact with others through this message board; $\alpha=.88$ ) (Stravositu \& Sundar, 2012). Seven items were dropped due to cross-loadings. ${ }^{3}$ A complete list of SOA and SOC measurement items can be found in the appendix.

\section{Behavioral outcomes}

A 7-point scale (anchored between describes very poorly and describes very well) with six adjectives (e.g., good, beneficial, pleasant, etc.; $\alpha=.85$ ) was used for gauging participants' attitude toward posting (Ajzen \& Fishbein, 1980). A three-item index on a scale anchored between extremely unlikely (1) and very much likely (7) $(\alpha=.90)$ was also used for measuring the likelihood of participants engaging in future posting activities in online communities (Ajzen \& Fishbein, 1980).

\section{Control variables}

Besides the dependent variables, the study administered a series of measures in order to control for participants' prior experiences with e-community activities via Facebook, product review sites, and online health message boards. In addition, the study assessed participants level of involvement with the health topic (i.e., fitness and nutrition) on a 7-point scale using 12 adjectives (e.g., important, of concern to me, relevant, etc.; $\alpha=.97$ ) (Zaichkowsky, 1985). Participants were also asked to rate the appropriateness of the membership badge that they received from the study website on a 7-point Likert scale using one item: "The membership status awarded to me is appropriate given my prior experience with these kinds of websites (e.g., community websites, online discussion forums, social networking sites, online product review websites, etc.)."

\section{Results}

Given that the interface cues were presented simultaneously rather than separately to participants, the present study employed an analysis of covariance where two independent variables - authority and bandwagon cues-and LOC as a moderating variable were entered along with the control variables in order to test our hypotheses.

\section{Manipulation checks}

Both source-cue manipulations were successful. When asked "What kind of membership seal did you receive from the website: online guru vs. member?" participants were significantly more likely to choose the former in the "high authority" condition compared to the "low authority" condition

\footnotetext{
${ }^{3}$ The cross-loading of seven items between SOA and SOC is unsurprising in the context of online message boards because the sense of agency that one obtains from activities in such forums is derived in part from the response that one gets from other members of the community. Therefore, SOA and SOC are likely to be more correlated in online message boards than in blogs (for which these scales were originally developed).
} 
(where they were more likely to choose the latter), $\chi^{2}(1,89)=34.08, p<.0001$. In addition, participants' perception of the level of their membership status on a 7-point scale $(1=$ very low to 7 $=$ very high $)$ also resulted in a significant difference between conditions, $t(81.97)=2.76, p<.01$ $\left(M_{\text {high }}=4.73, S D_{\text {high }}=1.69, n=41, M_{\text {low }}=3.70, S D_{\text {low }}=1.74, n=43\right.$; see Table 1$)$. The similar measures for the participants' perceptions on all of the bandwagon-cue manipulations indicated successful manipulations of the bandwagon cues as well, by showing significant differences (at $p<$ .001) between the weak- and strong-bandwagon conditions. See Table 2 for a summary of the results of the authority and bandwagon cue manipulations.

Table 2. Summary of manipulation checks.

\begin{tabular}{|c|c|c|c|c|}
\hline Variable & Manipulation check items & \multicolumn{2}{|c|}{ Mean $(S D)$} & t-Test $(d f)$ \\
\hline \multirow[t]{2}{*}{ Authority cue } & & $\operatorname{High}(n=41)$ & Low $(n=43)$ & \\
\hline & In your opinion, the level of your membership status in this health community website is... & $4.73(1.69)$ & $3.70(1.74)$ & $2.76(81.97)^{* *}$ \\
\hline \multirow{6}{*}{$\begin{array}{l}\text { Bandwagon } \\
\text { cues }\end{array}$} & & Strong $(n=41)$ & Weak $(n=43)$ & \\
\hline & $\begin{array}{l}\text { In your opinion, the number of people who VIEWED your thread is. . } \\
\text { (Very Few 1; A lot } 7 \text { ) }\end{array}$ & $5.78(1.27)$ & $3.51(1.72)$ & $6.88(77.31)^{* * *}$ \\
\hline & $\begin{array}{l}\text { In your opinion, the number of people who REPLIED to your thread is. . } \\
\text { (Very Few } 1 ; \text { A lot } 7 \text { ) }\end{array}$ & $4.88(1.65)$ & $2.05(.92)$ & $9.66(62.31)^{* * *}$ \\
\hline & $\begin{array}{l}\text { In your opinion, the number of times your thread was SHARED is. . } \\
\text { (Very Few } 1 ; A \text { lot } 7 \text { ) }\end{array}$ & $3.80(.25)$ & $1.86(.25)$ & $5.47(70.67)^{* * *}$ \\
\hline & $\begin{array}{l}\text { In your opinion, star ratings of helpfulness that your thread received is . . } \\
\text { (Very Low 1: Very High, 7) }\end{array}$ & $5.37(1.46)$ & $2.33(1.36)$ & $9.86(80.8)^{* * *}$ \\
\hline & Cumulative index of bandwagon cues & $4.96(1.25)$ & $2.44(.88)$ & $10.65(71.32)^{* * *}$ \\
\hline
\end{tabular}

${ }^{* *} p<.01,{ }^{* * *} p<.001$. One-tailed $t$-tests.

\section{Effects of sources cues and LOC on users' psychological outcomes}

A series of analysis of covariance was performed to test hypotheses that predicted interaction effects of the two source cues and users' LOC as the moderating variable on attitudes toward posting, intention to post, SOA and SOC. First, LOC yielded main effects on attitudes toward the posting activities, $F(1,70)=4.79, p<.05, \eta^{2}=.05$, intention to post, $F(1,70)=8.84, p<.01, \eta^{2}=.05$, and SOC, $F(1,70)=10.49, p<.01, \eta^{2}=.12$, such that the higher the score on LOC (i.e., higher external LOC and lower internal LOC), and the more positive were users' attitudes toward posting activities, the greater was the intention to post and the greater was the SOC. H1, H2, H3, and H4 were not supported since the interactions between LOC and each of the source cues were nonsignificant. LOC and the bandwagon cues yielded a two-way interaction effect on SOC that approached statistical significance, $F(1,70)=3.72, p=.06, \eta^{2}=.04$. Counter to H5b, those with high internal LOC were more reactive to the weak bandwagon cues and felt a lower sense of community, compared to those with high external LOC (Figure 3).

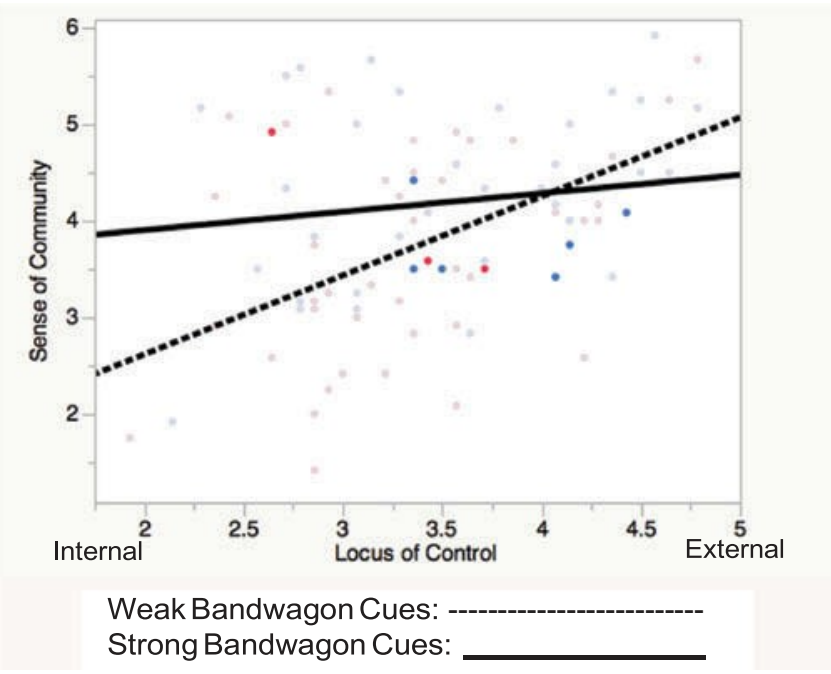

Figure 3. Two-way interaction effect between locus of control and bandwagon cues.

Lastly, LOC and the two source cues yielded a three-way interaction on SOA, $F(1,70)=6.78, p<$ $05, \eta^{2}=.06$, such that users' SOA was positively associated with internal LOC and negatively associated with external LOC in the presence of a high-authority cue, but the reverse was true in the presence of the low-authority cue (see left-hand-side graph in Figure 4). However, in the presence of 
strong bandwagon, LOC and authority cue do not appreciably affect SOA (right-hand-side graph of Figure 4). Thus, H5a and H6c were supported.

\section{Discussion}

Similar to the findings from previous studies (e.g., Lam \& Mizerski, 2005; Sandler \& Lakey, 1982), those with external LOC responded more positively to posting activities and showed stronger attachment to the community. However, when external reinforcement came into play, the sense of community (SOC) was higher with weak bandwagon cues rather than with strong ones among those with external LOC. On the contrary, for those with high internal LOC, SOC was higher with strong bandwagon cues than with weak ones (Figure 3). This positive responsiveness to the external reinforcement (i.e., bandwagon cues) among those with high internal LOC was still effective when the internal reinforcement (i.e., authority cue) was weak (right-hand-side graph of Figure 4). When the external reinforcement was weak, the internal reinforcement (i.e., authority cue) positively influenced their SOA, as hypothesized. However, the authority cue decreased SOA for those with high external LOC and without strong bandwagon cues (left-hand-side graph of Figure 4).

In sum, this three-way interaction among the two source cues and LOC shows that the effects of each source cue vary depending on users' LOC orientation. For users who possess strong internal LOC, authority cues are more effective than for those with strong external LOC in producing SOA when weak bandwagon cues were present. Furthermore, as seen in the two-way interaction, they also show greater SOC in the presence of strong, rather than weak, bandwagon cues. Therefore, those with internal LOC appear to be positively influenced by both interface cues in this study when they occur independently. However, their combined effects are somewhat complex. For example, cues signaling high authority and strong bandwagon, when they co-occur, tended to hinder SOA for those with internal LOC, while these did not matter to those with high external LOC (right-hand side of Figure 4). 


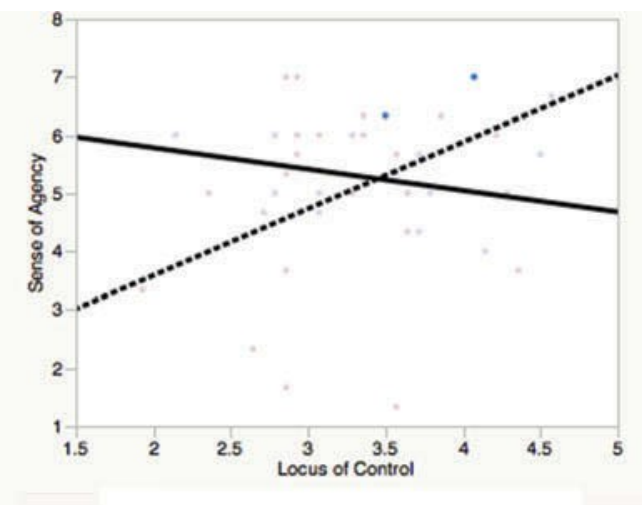

Weak Bandwagon Cues

Low Authority Cue:

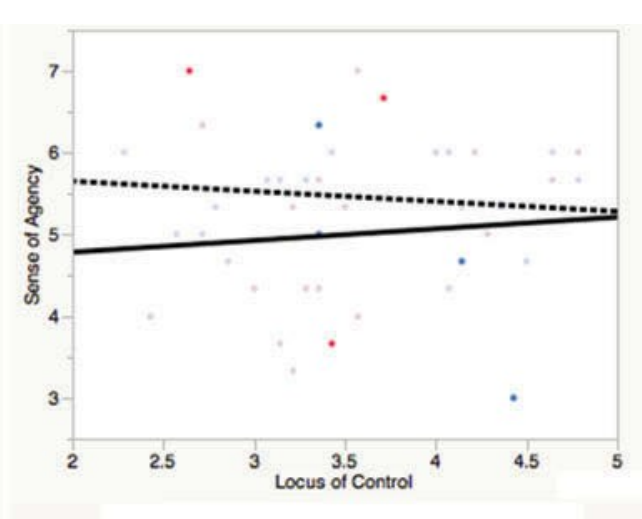

Strong Bandwagon Cues

High Authority Cue:

Figure 4. Three-way interaction effect between user LOC, authority cues (online guru vs. regular member), and bandwagon cues (weak vs. strong) on sense of agency.

Differential responses to the two source cues demonstrate how internal and external LOC seek out different reinforcements that fundamentally satisfy unique drivers for action (Rotter, 1966). Furthermore, user reactions toward each type of source cues converge upon conceptually matched psychological responses, SOA or SOC, depending on the user's personal trait-internal or external LOC, respectively. For a user with strong internal LOC, the authority cue caters to the user's preference for reinforcement that confirms and recognizes the user's own contribution to the community - hence, the greater SOA. Interestingly, the bandwagon cues also appear to acknowledge the contributions of users with strong internal LOC, leading to higher SOA, but only when the authority cue is weak. For users with strong external LOC, on the other hand, lack of community feedback (by way of weak bandwagon cues) appears to stimulate their SOC as well as SOA. External LOC is associated with a predisposition to seek others' validation to justify one's action (Rotter, 1966). Therefore, strong bandwagon cues possibly make drivers for the action wither, while weak bandwagon cues help amplify these drivers among users with strong external LOC. The addition of low authority cues to weak bandwagon cues serves to further stimulate their SOA, whereas high authority cues tend to dampen it. Together, these findings suggest that while high authority and strong bandwagon cues are fungible in enhancing the SOA of those with strong internal LOC, low authority and weak bandwagon serve to motivate those with external LOC.

\section{Psychology of cue-combination metrics and users' LOC orientations}

\section{Source cues and internal LOC}

The authority cue had a positive effect on SOA when the user has high internal LOC but when community feedback was weak (left-hand side of Figure 4). Previous research has suggested that those with high internal LOC visit online communities in order to gratify their own needs - seeking or providing help - rather than sticking around the community without reason like their counterparts with high external LOC (Hoffman et al., 2003; Lefcourt et al., 1973; Sandler \& Lakey, 1982). This is because internal LOC generally implies a self-centered, self-determined, and independent nature (Rotter, 1990). Therefore, it stands to reason that the appeals to uniqueness and expertise signified by the authority cue ("online guru") are appreciated by those with high internal LOC rather than those with high external LOC. However, the present study also found that those with high internal LOC also readily responded to positive community feedback to boost their SOC. However, such positive community feedback interfered with their SOA in the presence of high authority cue.

The literature suggests that online users are likely to contribute their expertise based on their experience in greater numbers if they find that their contributions are being noticed and used by other users (e.g., Civan, McDonald, Unruh, \& Pratt, 2009; Hartzler \& Pratt, 2011). People often think that their own contributions to an online community are rather trivial and hesitate to participate when they find that their efforts in a group are evaluated improperly (Karau \& Williams, 1995). Therefore, bandwagon cues usually provide visible endorsement from others as a common form of community feedback, and have shown positive effects on users' intentions to contribute to online health communities (Kim \& Sundar, 2011). However, such positive community feedback and attention from the community regarding posting activities undermined the effect of internal reinforcement (i.e., high 
authority cue) on feelings of competence and self-centeredness for those with high internal LOC, probably because they suspect that the high-authority status bestowed upon them is due to the strong bandwagon indicators rather than to the innate quality of their posting. Those with high internal LOC appear to have a strong preference for internal over external reinforcement for boosting their SOA. This result can be attributed to the fact that internal LOC, authority cue, and SOA all emphasize the concept of self-centeredness. The authority cue played a critical role in shaping the strong agentic feeling (SOA) because it catered to the preference for acknowledgment on what they initiated (i.e., posted) among users with strong internal LOC.

\section{Source cues and external LOC}

Unlike internal LOC, external LOC is based on dependence, providing excuses for one's actions, and the consequent likelihood of attributing results of one's actions to others (Rotter, 1990). Given this, we expected that the bandwagon cues, providing others' approval of one's actions, would be particularly likely to appeal to those with high levels of external LOC. However, on the contrary, we found that those with high external LOC showed high levels of SOA and SOC when the bandwagon cues were weak, not strong. It appears that weak bandwagon cues motivate those with strong external LOC to reaffirm their agency and importance of community. The weak cues could be priming them to think about ways to increase their influence, given their natural tendency to value others' feedback.

\section{Practical implications}

The findings of the present study suggest that those with internal LOC are indeed quite influenced by both authority and bandwagon cues, whereas those with external LOC seem to be affected primarily by the latter. While strong indicators of authority and bandwagon serve to imbue higher agency and community for those with internal LOC, weak bandwagon cues tend to motivate those with external LOC to profess higher senses of agency and community. Therefore, it is important for online health communities to deploy different strategies in designing their interface depending on possible, dominant individual LOC orientations of participants in their communities. For instance, an online health community for breast cancer patients who suffer from depression and anxiety (Naus, Price, \& Peter, 2005) or one dealing with obesity and diabetes (Gale, Batty, \& Deary, 2008; Sonntag et al., 2010; Wallston \& Wallston, 1978) is likely to be predominated by those with a stronger external LOC. For such a community, bandwagon cues of various kinds, which do not quickly confer their high status of community popularity, are important as motivational tools for them to contribute more and feel a sense of connection with others.

On the other hand, if an online health community attracts a number of cancer survivors or individuals who maintain good health conditions in terms of weight management, the site should highlight their authority status and provide strong bandwagon cues because these types of individuals typically demonstrate greater internal LOC (Bettencourt et al., 2008; De Valck \& Vinck, 1996). Upon entrance to an online community, newcomers typically encounter limited support from other community members, in the form of bandwagon cues, due to short history of their membership. Given the fact that these newcomers with a strong internal LOC trait still desire endorsement for their action performed in the community, the authority cue can serve this vital function. Moreover, the assignment of authority cues is likely to be seen as authentic even when awarded at the very beginning of their entry into the online community because cancer survivors would have detailed what they have gone through to fight the illness during the process of enrollment or when they introduce themselves to the community. It is also important to note that even those with strong internal LOC still appreciate community feedback to boost their feelings of community belongingness. However, simultaneous presentation of both source cues may not be the best strategy to encourage those users to contribute. Thus, the deployment of interface cues in an online community catering to individuals with a strong internal LOC orientation ought to be strategic, instead of assuming "the more, the better."

\section{Limitations}

A major limitation of the present study is that participants were asked to initiate posting as an experimental task. Therefore, it is unclear whether the findings pertaining to the effect of cues on psychological responses of those with internal and external LOC can be generalized to those who post in online forums out of their own volition. The motivational forces underlying their behavior may be stronger than the validation provided by the system in the form of authority badges and community feedback. Nevertheless, the findings are informative, especially when targeting individuals of different LOC orientations for appeals to contribute to online health communities.

Another limitation is that the topics used for the experiment (general diet and nutrition) were not particularly contentious so as to generate a great deal of debate. It is unclear whether the LOC 
orientations and the source cues will play as significant a role in forums where the topics are more amenable to discussion. They may be more significant, boosting the level of user participation in the online community.

Despite concerns about information overload, inequality of information, and lack of credibility of peer-to-peer communication (Cline \& Haynes, 2001; Eastin, 2001; Metzger, 2007; Southwell, 2013), higher levels of participation will lead to a greater possibility of detecting and correcting erroneous information, airing of unconventional approaches, vigorous debate, and so on - all contributing to the overall health of the information environment. Our study adds to the growing literature on encouraging user contribution online (e.g., Farzan et al., 2008; Karau \& Williams, 1995; Kim \& Sundar, 2011; Lampe et al., 2010; Ling et al., 2005) by highlighting the importance of appealing to individuals' locus of control when designing affordances and metrics for motivating users. By strategically targeting users with different levels of internal and external LOC and providing them affordances that promise higher senses of agency and community, we can convert more lurkers into posters and thereby increase the vitality of discourse in online health communities.

\section{References}

Ajzen, I., \& Fishbein, M. (1980). Understanding attitudes and predicting social behavior. Englewood Cliffs, NJ: Prentice Hall.

Alexa.com. (2010). Alexa. Retrieved from http://www.alexa.com Amichai-Hamburger, Y., Lamdan, N., Madiel, R., \& Hayat, T. (2008). Personal characteristics of Wikipedia members.

CyberPsychology \& Behavior, 11, 679-681. doi:10.1089/cpb.2007.0225

Barak, A., Boniel-Nissim, M., \& Suler, J. (2008). Fostering empowerment in online support groups. Computers in Human Behavior, 24, 1867- 1883. doi:10.1016/j.chb.2008.02.004

Baxter, L., Egbert, N., \& Ho, E. (2008). Everyday health communication experiences of college students. Journal of American College Health, 56, 427-436. doi:10.3200/JACH.56.44.427-436

Bettencourt, B. A., Talley, A. E., Molix, L., Schlegel, R., \& Westgate, S. J. (2008). Rural and urban breast cancer patients: Health locus of control and psychological adjustment. Psycho-Oncology,

17, 932-939. doi:10.1002/pon.v17:9

Bishop, J. (2007). Increasing participation in online communities: A framework for human-computer interaction. Computers in Human Behavior, 23, 1881-1893. doi:10.1016/j.chb.2005.11.004

Buchanan, H., \& Coulson, N. S. (2007). Accessing dental anxiety online support groups: An exploratory qualitative study of motives and experiences. Patient Education \& Counseling, 66, 263-269. doi:10.1016/j.pec.2006.12.011

Chen, M.-L., Deng, S.-L., \& Chang, H.-K. (2001). A comparison of the health locus of control and

perceived social support between cancer and AIDS patients. Scandinavian Journal of Caring Sciences, 15, 92-98. doi:10.1046/j.1471-6712.2001.1510092.x

Civan, A., McDonald, D. W., Unruh, K. T., \& Pratt, W. (2009). Locating patient expertise in everyday life. Proceedings of International Conference on Support Group Work (SIGCHI' 09), 291-300. doi:10.1109/HICSS.2005.444

Cline, R. J. W., \& Haynes, K. M. (2001). Consumer health information seeking on the Internet: The state of art. Health Education Research, 16, 671-692. doi:10.1093/her/16.6.671

Curtrona, C. (1990). Stress and social support: In search of optimal matching. Journal of Social Clinical Psychology, 9, 3-14. doi:10.1521/ jscp.1990.9.1.3

De Valck, C., \& Vinck, J. (1996). Health locus of control and quality of life in lung cancer patients. Patient Education and Counseling, 28, 179-186. doi:10.1016/0738-3991(96)00897-X

Eastin, M. S. (2001). Credibility assessments of online health information: The effects of source expertise and knowledge of content. Journal of Computer-Mediated Communication, 6(4). Retrieved from http:// jcmc.indiana.edu/vol6/issue4/eastin.html

Farzan, R., DiMicco, J. M., Millen, D. R., Brownholtz, B., Geyer, W., \& Dugan, C. (2008). Results from deploying a participation incentive mechanism within the enterprise. In CHI proceedings (pp. 563-572). Florence, Italy: ACM Press. doi:10.1145/1357054.1357145

Fox, S.,\& Duggan, M. (2013). Health online 2013. Retrieved from http://www. pewinternet.org/files/old-media//Files/Reports/PIP_HealthOnline.pdf

Fox, S., \& Jones, S. (2009). The social life of health information. Retrieved from http://www.pewinternet.org/Reports/2009/8-The-Social-Life-of-Health-Information.aspx

Gale, C. R., Batty, G. D., \& Deary, I. J. (2008). Locus of control at age 10 years and health outcomes and behaviors at age 30 years: The 1970 British cohort study. Psychosomatic Medicine, 70, $397-$ 403. doi:10.1097/PSY.0b013e31816a719e

Hann, D., Bake, F., Denniston, M., Gesme, D., Reding, D., \& Flynn, T. (2002). The influence of social support on depressive symptoms in cancer patients: Age and gender differences. Journal of Psychosomatic Research, 52, 279-283. doi:10.1016/S0022-3999(01)00235-5

Hartzler, A., \& Pratt, W. (2011) Managing the personal side of health: How patient expertise differs from the expertise of clinicians. Journal of Medical Internet Research, 13(3), e62. 
doi:10.2196/jmir.1728

Hennig-Thurau, T., Gwinner, T., Walsh, G., \& Gremler, D. D. (2004). Electronic word-of-mouth via consumer-opinion platforms: What motivates consumers to articulate themselves on the Internet? Journal of Interactive Marketing, 18(1), 38-52. doi:10.1002/dir.10073

Hoffman, D. L., Novak, T. P., \& Schlosser, A. E. (2003). Locus of control, Web use, and consumer attitudes toward Internet regulation. Journal of Public Policy \& Marketing, 22, 41-57. doi:10.1509/ jppm.22.1.41.17628

Karau, S. J., \& Williams, K. D. (1995). Social loafing: Research findings, implications, and future directions. Current Directions in Psychological Science, 4(5), 134-140. doi:10.1111/14678721.ep10772570

Kim, H. S., \& Sundar, S. S. (2011). Using interface cues in online health community boards to change impressions and encourage user contribution. Proceedings of the 2011 Annual Conference on Human Factors in Computing Systems (CHI'11), 599-608.

Kruglanski, A. W. (1975). The human subject in the psychology experiment: Fact and artifact. In L. Berkowitz (Ed.), Advances in experimental social psychology (pp. 101-147). New York, NY: Academic Press.

Lam, C. D., \& Mizerski, R. W. (2005). The effects of locus of control on word-of-mouth communication. Journal of Marketing Communications, 11, 215-228. doi:10.1080/1352726042000333180

Lampe, C., Walsh, R., Velasquez, A., \& Ozkaya, E. (2010). Motivations to participate in online communities. Proceedings of the 2010 Annual Conference on Human Factors in Computing Systems (CHI'10), 1604- 1613. doi:10.1145/1753326.1753616

Latané, B. (1981). The psychology of social impact. American Psychologist, 36, 343-356. doi:10.1037/0003-066X.36.4.343

Lefcourt, H. M., Gronnerud, P., \& McDonald, P. (1973). Cognitive activity and hypothesis formation during a double entendre word association test as a function of locus of control and field dependence. Canadian Journal of Behavioral Science, 5, 161-173. doi:10.1037/ h0082341

Levenson, H. (1974). Activism and powerful others: Distinctions within the concept of internalexternal control. Journal of Personality Assessment, 38, 377-383. doi:10.1080/00223891.1974.10119988

Ling, K., Beenen, G., Ludford, P., Wang, X., Chang, K., Li, X., Cosley, D., ... Kraut, R. (2005). Using social psychology to motivate contributions to online communities. Journal of Computer-Mediated Communication, 10(4), article 10. doi:10.1111/j.1083-6101.2005. tb00273.x

Ma, M., \& Agarwal, R. (2007). Through a class darkly: Information technology design, identity verification, and knowledge contribution in online communities. Information System Research, 18(1), 42-67. doi:10.1287/isre.1070.0113

Metzger, M. J. (2007). Making sense of credibility on the Web: Models for evaluating online information and recommendations for future research. Journal of American Society for Information Science and Technology, 58, 2078-2091. doi:10.1002/asi.20672

Mo, P. K. H., \& Coulson, N. S. (2010). Empowering processes in online support groups among people living with HIV/AIDS: A comparative analysis of 'lurkers' and 'posters.' Computer in Human Behavior, 26, 1183-1193. doi:10.1016/j.chb.2010.03.028

Mo, P. K. H., \& Coulson, N. S. (2012). Developing a model for online support group use, empowering processes and psychological outcomes for individuals living with HIV/AIDS. Psychology and Health, 27, 445-459. doi:10.1080/08870446.2011.592981

Naus, M. J., Price, E. C., \& Peter, M. P. (2005). The moderating effects of anxiety and breast cancer locus of control on depression. Journal of Health Psychology, 10, 687-694. doi:10.1177/ 1359105305055324

Nov, O. (2007). What motivates Wikipedians? Communications of the ACM, 50(11), 60-64. doi: $10.1145 / 1297797$

Oh, S. (2012). The characteristics and motivations of health answerers for sharing information, knowledge, and experiences in online environments. Journal of the American Society for Information Science and Technology, 63, 543-557. doi:10.1002/asi.v63.3

Oliver, P. E., \& Marwell, G. (1988). The paradox of group size in collective action: A theory of the critical mass. II. American Sociological Review, 53, 1-8. doi:10.2307/2095728

Pentzold, C. (2010). Imagining the Wikipedia community: What do Wikipedia authors mean when they write about their "community"? New Media \& Society, 13, 704-721. doi:10.1177/ 1461444810378364

Prasarnphanich, P., \& Wagner, C. (2011). Explaining the sustainability of digital ecosystems based on the Wiki model through critical-mass theory. IEEE Transaction on Industrial Electronics, 58, 2065-2072. doi:10.1109/TIE.2009.2027248

Preece, J., Nonnecke, B., \& Andrews, D. (2004). The top five reasons for lurking: Improving community experiences for everyone. Computers in Human Behavior, 20, 201-223. doi:10.1016/j. chb.2003.10.015

Ridings, C. M., \& Gefen, D. (2004). Virtual community attraction: Why people hang out online. Journal of Computer-Mediated Communication, 10(1), Article 4. Retrieved from 
http://jcmc.indiana.edu/vol10/issue1/ridings_gefen.html

Rotter, J. B. (1954). Social learning and clinical psychology. Englewood Cliffs, NJ: Prentice Hall. doi: $10.1037 / 10788000$

Rotter, J. B. (1966). Generalized expectancies for internal versus external control of reinforcement. Psychological Monographs, 80, 1-28. doi:10.1037/h0092976

Rotter, J. B. (1990). Internal versus external control of reinforcement. American Psychologist, 45, 489-493. doi:10.1037/0003-066X.45.4.489

Sandler, I. N., \& Lakey, B. (1982). Locus of control as a stress moderator: The role of control perceptions and social support. American Journal of Community Psychology, 10, 65-80. doi:10.1007/BF00903305

Sonntag, U., Esch, T., Von Hagen, L., Rennenberg, B., Braun, V., \& Helntze, C. (2010). Locus of control, self-efficacy and attribution tendencies in obese patients: Implications for primary care consultation. Medical Science Monitor, 16(7), CR330-335. Retrieved from http://www.medscimonit.com/fulltxt.php?ICID=880928

Southwell, B. G. (2013). Social networks and popular understanding of science and health: Sharing disparities. Baltimore, MD: Johns Hopkins University Press.

Stavrositu, C., \& Sundar, S. S. (2012). Does blogging empower women? Exploring the role of agency and community. Journal of Computer-Mediated Communication, 17, 369-386. doi:10.1111/j.10836101.2012.01587.x

$\mathrm{Su}, \mathrm{C}$. (2012). Who knows who knows what in the group? The effects of communication network centralities, use of digital knowledge repositories, and work remoteness on organizational members' accuracy in expertise recognition. Communication Research, 39, 614-640. doi: $10.1177 / 0093650211433825$

Sundar, S. S. (2008). Self as source: Agency and customization in interactive media. In E. A. Konijn, S. Utz, M. Tanis, \& S. B. Barnes (Eds.), Mediated interpersonal communication (pp. 58-74). Mahwah, NJ: Lawrence Erlbaum Associates.

Sundar, S. S., \& Nass, C. (2001). Conceptualizing sources in online news. Journal of Communication, 51, 52-72. doi:10.1111/j.1460-2466.2001. tb02872.x

Sundar, S. S., Xu, Q., \& Oeldorf-Hirsch, A. (2009). Authority vs. peer: How interface cues influence users. Proceedings of the 27th International Conference Extended Abstracts on Human Factors in Computing Systems (CHI'09), 27, 4231-4236.

Tedjamulia, S. J. J., Olsen, D. R., Dean, D. L., \& Albrecht, C. C. (2005). Motivating content contributions to online communities: Toward a more comprehensive theory. Proceedings of the 38th Annual Hawaii International Conference on System Sciences. doi:10.1109/HICSS.2005.444

Thorn, B. K., \& Connolly, T. (1987). Discretionary databases: A theory and some experimental findings. Communication Research, 14, 512- 528. doi:10.1177/009365087014005004

Van Uden-Kraan, C. F., Drossaert, C. H. C., Taal, E., Seydel, E. R., \& Van De Laar, M. A. F. J. (2009). Participation in online patient support groups endorses patients' empowerment. Patient Education and Counseling, 74, 61-69. doi:10.1016/j.pec.2008.07.044

Vanderzee, K. I., Buunk, B. P., \& Sanderman, R. (1997). Social support, locus of control, and psychological well-being. Journal of Applied Social Psychology, 27, 1842-1859. doi:10.1111/jasp.1997.27. issue-20

Wallston, B. S., \& Wallston, K. A. (1978). Locus of control and health: A review of the literature. Health Education \& Behavior, 6, 107-117. doi:10.1177/109019817800600102

Wallston, K. A. (1992). Hocus-pocus, the focus isn't strictly on locus: Rotter's social learning theory modified for health. Cognitive Therapy and Research, 16, 183-199. doi:10.1007/ BF01173488

Wallston, K. A. (2005). The validity of the multidimensional health locus of control scales. Journal of Health Psychology, 10, 623-631. doi:10.1177/1359105305055304

Wasko, M. M., \& Faraj, S. (2000). "It is what one does": Why people participate and help others in electronic communities of practice. Journal of Strategic Information System, 9, 155-173. doi:10.1016/ S0963-8687(00)00045-7

Wasko, M. M., \& Faraj, S. (2005). Why should I share? Examining social capital and knowledge contribution in electronic networks of practice. MIS Quarterly, 29(1), 35-57. Retrieved from http://www.jstor.org/pss/ 25148667

Wolk, S., \& DuCette, J. (1974). Intentional performance and incidental learning as a function of personality and task directions. Journal of Personality and Social Psychology, 29, 90-101. doi:10.1037/ h0035687

Wright, K. B., Johnson, A. J., Bernard, D. R., \& Averbeck, J. (2011). Computer-mediated social support: Promises and pitfalls for individuals coping with health concerns. In T. Thompson, R. Parrott, \& J. Nussbaum (Eds.), The Routledge handbook of health communication (2nd ed., pp. 349-362). London, UK: Routledge.

Yuan, Y. C., Bazarova, N. N., Fulk, J., \& Zhang, Z.-X. (2013). Recognition of expertise and perceived influence in intercultural collaboration: A study of mixed American and Chinese groups. Journal of Communication, 63, 476-497. doi:10.1111/jcom.12026

Zaichkowsky, J. L. (1985). Measuring the involvement construct. Journal of Consumer Research, 12, 
341-352. doi:10.1086/208520

Zhang, W., \& Storck, J. (2001). Peripheral members in online communities. Proceedings of the Americas Conference on Information Systems, Boston, MA. Paper 117. Retrieved from http://aisel.aisnet.org/amcis2001/117

Zhao, S. J., Zhang, K. Z. K., Wagner, C., \& Chen, H. (2013). Investigating the determinants of contribution value in Wikipedia. International Journal of Information Management, 33(1), 83-92. doi:10.1016/j. ijinfomgt.2012.07.006

\section{Appendix: a complete list of measurement items for sense of agency and sense of community}

"You've thought about the activity of posting a question or replying to the thread in the message board. With this in mind, please imagine what types of outcomes these activities (that is, posting or replying) might have for you. Then, indicate the degree to which each of the following statements describes the outcomes of your posting/replying activity": (1, Not at all; 7, A lot)

Sense of agency $(\alpha=.71)$

I have control over my own voice. I assert myself.

I have a distinct voice.

Sense of community $(\alpha=.88)$

I feel at home in this message board.

I care about what readers think of my views and actions.

It may well become very important to me to interact with others through this message board.

People posting and replying to this message board will not get along with each other.

(Reverse coded)

I expect to get a lot of interacting with others through this message board.

I expect to support from those users in the message board.

I expect that some of the users of this message board will be friends with each other.

I expect to have friends among those who are users in this community website.

I expect that some users in this community website can be counted on to help others.

I might feel obligated to help others through this message board. I think I will like users on this message board.

I feel other users on this message board will mean a lot to me.

Cross-loaded items

I feel I am part of a larger community.

I connect very well with other users in the community.

A space that allows others to participate, like the message board, is a good place for me to be in.

People who comment on message boards do not all share the same values. (Reverse coded)

Other users in the health community website and I want the same thing from participating

in this message board.

I don't expect to have any influence over what other users are like. (Reverse coded)

I expect that if I raise questions in this message board they will be answered by other users. 